\title{
Design and Development of Symmetrical E-Shaped Microstrip Patch Antenna for Multiband Wireless Applications
}

\author{
Pavneet Kaur ${ }^{1}$, Gurmohan Singh ${ }^{2}$, Jaspal Singh ${ }^{3}$ and Manjit Kaur ${ }^{4}$ \\ ${ }^{1}$ Research Scholar, ACS Division, C-DAC, Mohali, India-160071 \\ ${ }^{2}$ Senior Engineer, DEC Division, C-DAC, Mohali, India-160071 \\ ${ }^{3}$ Principal Engineer, DEC Division, C-DAC, Mohali, India-160071 \\ ${ }^{4}$ Engineer, ACS Division, C-DAC, Mohali, India-160071 \\ 1pavneetkaur76@gmail.com, ${ }^{2}$ gurmohan@cdac.in, ${ }^{3}$ jaspal@cdac.in, \\ ${ }^{4}$ Manjeet@cdac.in
}

\begin{abstract}
Microstrip patch antennas have made great advancements in wireless communication field in recent years. They have many advantages like light weight, low cost, smaller size, easy fabrication, high data rates, and capability to operate at multiband and wideband. They can be directly printed on a PCB and are gaining popularity in mobile phones. As the demand of operational bands increases, the design procedure of microstrip antenna is becoming very difficult. The microstrip antenna must be compact in size to employ them in miniaturized portable devices. Microstrip antenna comprise of rectangle, square, circle, triangle, donut, and dipole shaped patches. This paper presents design and development of a microstrip patch antenna for multiband wireless applications. The proposed geometry contains a substrate having rectangular radiating patch with symmetrical E-shaped slots on one side and a ground plane on other side. The designed miniaturized antenna has dimensions of $25 \times 25 \times 1.58 \mathrm{~mm}$. The performance parametersoperating frequency, return loss $\left(S_{11}\right)$, and voltage standing wave ratio (VSWR) are computed for the designed geometry. The fabricated antenna exhibits five frequency bands from 6.166 to $10.500 \mathrm{GHz}$. The computed return loss values are -14.9, -10.7, -14.3, -13.5 and $-14.6 \mathrm{~dB}$ at frequencies $6.166,6.833,8.166,9.500$ and $10.500 \mathrm{GHz}$ respectively. The observed VSWR values for the resonant frequency peaks are 1.43, 1.82, $1.48,1.54$ and 1.46 respectively. The values obtained for VSWR (between 1 and 2) and $S_{11}$ (below -10dB) are within recommended range for the desired frequency bands. FR4 substrate is used for the fabrication of the antenna having permittivity of 4.4. The performance parameters of fabricated antenna geometry are computed using VNA tool.
\end{abstract}

Keywords: Microstrip patch antenna (MPA), Bandwidth, VSWR, Magnitude, Return Loss $\left(S_{11}\right)$, Coaxial Probe Feed, Multi slot Antenna

\section{Introduction}

Microstrip Patch antenna structures are widely known for their planar profile, low fabrication cost, light weight, and mechanical robustness [1]. They are in more demand due to their compact size, multiband operation, and easy fabrication methods. Circularly polarized antennas are attractive for wireless applications as they exhibit the characteristics of Microstrip antennas [2]. Nowadays, many integration techniques such as Microwave Monolithic Integrated Circuits (MMICs) and Hybrid Microwave Integrated Circuits (HMIS) have been introduced [2]. Microstrip patch antennas are employed in many applications such as mobile phones, radio frequency identification (RFID), global positioning system (GPS), television, multiple input multiple output (MIMO) systems, satellites, guidance of missiles, radars, and medical imaging [1]. Microstrip antennas 
comprise of patches of different shapes. Patches are available rectangle, square, circle, triangle, donut, dipole shapes [1-2]. These antennas are mostly employed in portable devices and hidden inside the devices like radios or computers, providing Wi-Fi facility.

\subsection{Classification of Antennas}

\subsubsection{On the Basis of Radiation}

Omni directional Antennas: They propagate in all directions. They are also called weakly directional antennas. Radiations may be intense or poor in any particular direction [8].

Directional Antennas: The RF energy is focused in one or two directions. The signal strength of the antenna is higher as the same amount of RF energy is distributed over less area. These are also referred to as beam antennas since they radiate and receive in a particular direction. They can cover an area by combining EM field in a specific direction [8].

\subsubsection{On the Basis of Aperture}

Microstrip Antenna: They are having a substrate on which a radiating patch is present on the upper side, and a ground plane on the other side. They show a variety of use in wireless and space applications [9].

Aperture Antennas: They are highly developed antennas which perform at higher frequencies. As they can be easily fixed on the surfaces, they are suitable for aircraft and space applications [9].

Wire Antennas: They comprise of a long wire intermitted above the ground. The length of the wire is not dependent on the wavelength of the radio waves used, but it should be finalized precisely [9].

Array Antennas: They consist of individual antennas connected together in form of array which transmit or receive radio waves, so that their individual currents provide some particular phase and amplitude relationship in a particular direction [9].

\subsection{Antenna Parameters}

The performance of the antenna is characterized by the antenna parameters [9]. The following performance parameters are generally used to characterize designed antenna structure.

- Return Loss: It is the interference with the amount of power between the transmitted and the reflected signal, i.e., the power which is lost to the load and does not get reflected back [18]. This difference in the power is caused by the deviation in link and channel impedance. Hence, it is used to denote the matching between the transmitter and the antenna. The parameter used to calculate the amount of reflected power due to discrepancy from transmission line is known as $S_{11}$ parameter. The calculated power is described in decibels (dB) with negative value, more the negative value, less the return loss. Let the transmitted power be ' $\mathrm{P}_{\mathrm{t}}$ ', the reflected power be ' $\mathrm{P}_{\mathrm{r}}$ ' then the return loss (RL) is computed using equation (1) $[7,10]$.

$$
R L=-20 \log _{1 \mid}|\Gamma|
$$

Where, $|\Gamma|$ is reflection coefficient.

- Radiation Pattern: The graphical representation of the distributed radiated energy of the antenna in different directions in space is known as radiation 
pattern. The pattern is two-dimensional in rectangular and three-dimensional in polar plot format [9].

- Gain: It is the ratio of intensity of the antenna radiations in a particular direction, to the radiation intensity of an isotropic antenna [21]. In case of isotropic radiation, it is lossless and it radiates in all directions uniformly [12].

$$
\begin{gathered}
\text { Gain }=4 \Pi * \frac{\text { Radiation Intensity }}{\text { Total Input }} \\
\text { Gain }=4 \Pi U(\theta, \phi)
\end{gathered}
$$

- VSWR: The ratio of the minimum to the maximum antenna voltage is defined as the VSWR (Voltage Standing Wave Ratio) [7, 10]. The VSWR can be computed from reflection coefficient as described by equation (4).

$$
V S W R=\frac{|\Gamma|+1}{|\Gamma|-1}
$$

Where $|\Gamma|=\rho$

$$
\begin{aligned}
& \rho=|\Gamma|=\frac{V S W R-1}{V S W R+1} \\
& \Gamma=\frac{Z_{\text {input }}-Z_{0}}{Z_{\text {input }}+Z_{0}}
\end{aligned}
$$

\section{Related Work}

M. I. Nawaz et al. presented a review on the study of different techniques for Microstrip patch antenna design [1]. P. K. Deb et al. presented a patch designed on FR-4 substrate having E-shape covering $\mathrm{C}$ and $\mathrm{X}$ band frequencies providing a gain of $7 \mathrm{~dB}$ [3]. T. F. A. Nayna et al. designed a convex pentagon fractal patch antenna for multiple resonances providing $25.56 \%$ reduction in patch size in comparison to microstrip patches [4]. W. Afzal et al. designed an L-shaped patch antenna having maximum gain of $7.05 \mathrm{~dB}$ using HFSS simulator [6]. H. K. Dubey et al. designed rectangular patch on GML-1000 substrate having dielectric constant of 3.2, with four narrow slots and a ground plane [11]. A. Elrashidi et al. designed a rectangular patch antenna and computed resonance frequency, gain, efficiency, quality factor and fringing fields with the help of different substrates [12]. A. Singh et al. presented a novel trapezoidal shape for $\mathrm{THz}$ applications with thin microstrip line for coupling on a photonic crystal substrate exhibiting a wider bandwidth [13]. S. A. H. Saghanezhad et al. investigated a U-shape and inverted U-shape metamaterial substrate under the patch providing $77 \%$ miniaturization as compared to conventional patch antenna [14]. A. Singh et al. carried out a comparative study of circular and rectangular patch with the help of CST microwave studio, with patch thickness of 0.05 $\mathrm{mm}$ and dielectric constant of substrate 2.2 [15]. J. Abraham et al. described a CPW fed monopole patch antenna fabricated on FR-4 epoxy substrate for wireless applications [16]. A. Majumder designed H-shaped patch on FR-4 substrate having thickness of $6.7 \mathrm{~mm}$ for Bluetooth applications with operating frequency $2.4 \mathrm{GHz}$ [17]. Nazimuddin et al. compared circular, square, ring and cross shaped patch using circular polarization [18]. I. Singh et al. presented a rectangular patch to cover telemetry applications in S band on reactive impedance substrate providing $10 \%$ of impedance bandwidth [20]. H. Patel et al. presented design of a novel meandered square patch structure on FR-4 substrate exhibiting high gain, low profile and multiband applications covering L, S, C and X-band [21]. M. D. Sharma et al. designed an E-shape patch having circular polarization providing $16.4 \%$ 
bandwidth and 1.5 VSWR [22]. Y. Kumar et al. presented a compact low cost multiband hybrid fractal antenna by integrating a Koch curve and Minkowski curve for wireless mobile applications [24]. Y. Kumar et al. designed a hybrid fractal multiband antenna using Koch and meander geometry. They also analyzed the characteristics of the designed antenna [25]. Y. Kumar et al. presented a design of hybrid fractal multiband antenna using Koch curve and Meander antenna. They employed scripting method (*.vbs) to compute structural details using IFS and MATLAB.

\section{Antenna Design Procedure}

The designing of microstrip patch antenna includes the calculation of parameters such as: Resonant Frequency $\left(\mathrm{F}_{\mathrm{r}}\right)$, Effective Dielectric Constant $\left(\varepsilon_{\mathrm{r})}\right.$ and height (h) [3]. It is necessary to select the appropriate resonant frequency, so that the antenna can operate properly in wireless applications. Dielectric constant of the substrate $\left(\varepsilon_{\mathrm{r}}\right)$ depends on the substrate material and need to be selected properly as it plays a very important role in the designing of the antenna. As the value of the dielectric constant increases, the dimensions of the antenna decreases. But more the dielectric constant, more it interferes with the performance of the antenna. There exists a tradeoff between antenna size and its performance. The microstrip patch antenna should be light in weight and should not be bulky. Normally, the height is kept between 1.58 to $1.6 \mathrm{~mm}$. After selecting the above parameters, few calculations need to be made.

\section{Step 1: Calculation of Width (W)}

The width of the microstrip patch antenna affects the input impedance and bandwidth of the antenna [27]. It can be calculated as described by equation (7):

$$
W=\frac{C}{2 f_{0}\left(\frac{\varepsilon_{r}+1}{2}\right)^{\frac{1}{2}}}
$$

\section{Step 2: Calculation of Effective Dielectric Constant $\left(\mathcal{\varepsilon}_{\text {reff }}\right)$}

The effective dielectric constant affects the radiation characteristics of the microstrip patch antenna [27]. It can be computed using equation (8):

$$
\varepsilon_{\text {reff }}=\left(\frac{\varepsilon_{r}+1}{2}\right)+\left(\frac{\varepsilon_{r}-1}{2}\right)\left[1+12\left(\frac{h}{w}\right)\right]^{-\frac{1}{2}}
$$

\section{Step 3: Calculation of effective length $\left(\mathbf{L}_{\mathrm{eff}}\right)$}

The effective length [27] is computed using equation (9).

$$
L_{\text {eff }}=\frac{C}{2 f_{0}\left(\varepsilon_{\text {reff }}\right)^{\frac{1}{2}}}
$$

\section{Step 4: Calculation of the length extension $(\Delta L)$}

The length extension [27] can be calculated using equation (10):

$$
\frac{\Delta L}{h}=0.412 \frac{\left(\varepsilon_{\text {reff }}+0.3\right)\left(\frac{W}{h}+0.264\right)}{\left(\varepsilon_{\text {reff }}-0.258\right)\left(\frac{W}{h}+0.8\right)}
$$




\section{Step 5: Calculation of actual patch length $(\mathrm{L})$}

The actual length of radiating patch is dependent on the effective length and length extension [27]. It is computed using equation (11):

$$
L=L_{e f f}-2 \Delta L
$$

\section{Step 6: Calculation of ground dimensions $\left(\mathrm{L}_{\mathrm{g}}, \mathrm{W}_{\mathrm{g}}\right)$}

Although the transmission line model is suitable for infinite ground planes. But for practical applications, finite plane should be there. The size of the ground plane should be more than the patch size [27]. The ground plane dimensions [3] are calculated using equations (12) band (13)

$$
\begin{aligned}
& L_{g}=6 h+L \\
& W_{g}=6 h+W
\end{aligned}
$$

\section{Proposed Antenna Geometry}

The Figure 1 shows the geometry of proposed microstrip patch antenna structure. The Table 1 lists the optimal parameters of the proposed antenna geometry.

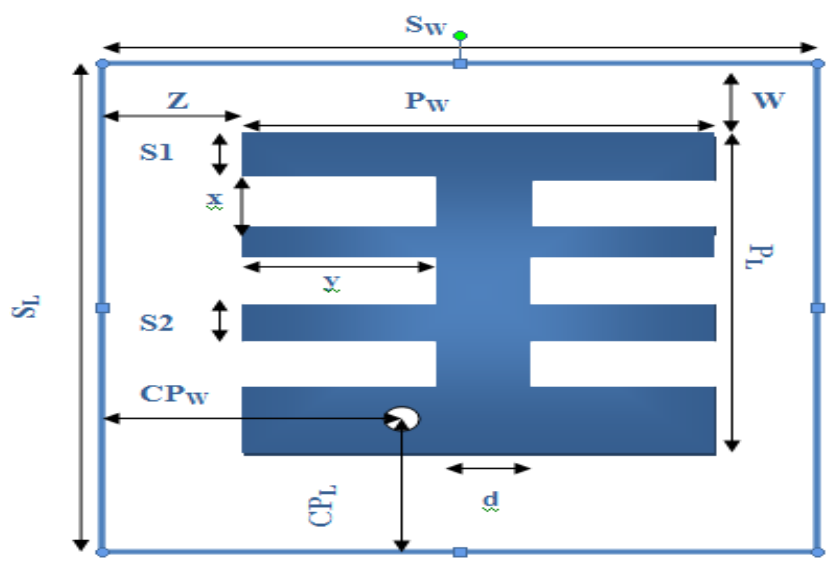

Figure 1. Geometry of Proposed Microstrip Patch Antenna

Table 1. Optimal Parameters of the Proposed Geometry

\begin{tabular}{|c|c|c|c|}
\hline Parameter & Size (mm) & Parameter & Size (mm) \\
\hline $\mathrm{S}_{\mathrm{L}}$ & 25 & $\mathrm{x}$ & 2 \\
\hline $\mathrm{S}_{\mathrm{W}}$ & 25 & $\mathrm{y}$ & 9 \\
\hline $\mathrm{P}_{\mathrm{L}}$ & 20 & $\mathrm{CP}_{\mathrm{L}}$ & 4.25 \\
\hline $\mathrm{P}_{\mathrm{W}}$ & 22.5 & $\mathrm{CP}_{\mathrm{W}}$ & 9 \\
\hline $\mathrm{G}_{\mathrm{L}}$ & 25 & $\mathrm{D}_{\mathrm{C}}($ core $)$ & 1.2 \\
\hline $\mathrm{G}_{\mathrm{W}}$ & 25 & $\mathrm{D}_{\mathrm{t}}($ Teflon $)$ & 2.5 \\
\hline $\mathrm{W}$ & 2.5 & $\mathrm{D}_{\mathrm{S}}($ circle) & 2.5 \\
\hline $\mathrm{Z}$ & 1.25 & $\mathrm{~S} 1$ & 4.5 \\
\hline $\mathrm{d}$ & 4.5 & $\mathrm{~S} 2$ & 2 \\
\hline
\end{tabular}




\section{Simulations and Results}

The parameters such as return loss, voltage standing wave ratio (VSWR) and gain have been computed with the help of simulations in the EM Field Solver tool. The designed antenna geometry is fabricated on FR4 substrate having permittivity of 4.4 and thickness of $1.6 \mathrm{~mm}$. The fabricated antenna is physically tested with the help of VNA tool. The maximum gain achieved is $6.7 \mathrm{~dB}$.

The Figure 2 shows the return loss $\left(S_{11}\right)$ of the simulated geometry. The simulation results demonstrate five resonant peaks having return loss less than $-10 \mathrm{~dB}$. The Figure 3 describes the VSWR plot for the simulated antenna structure.

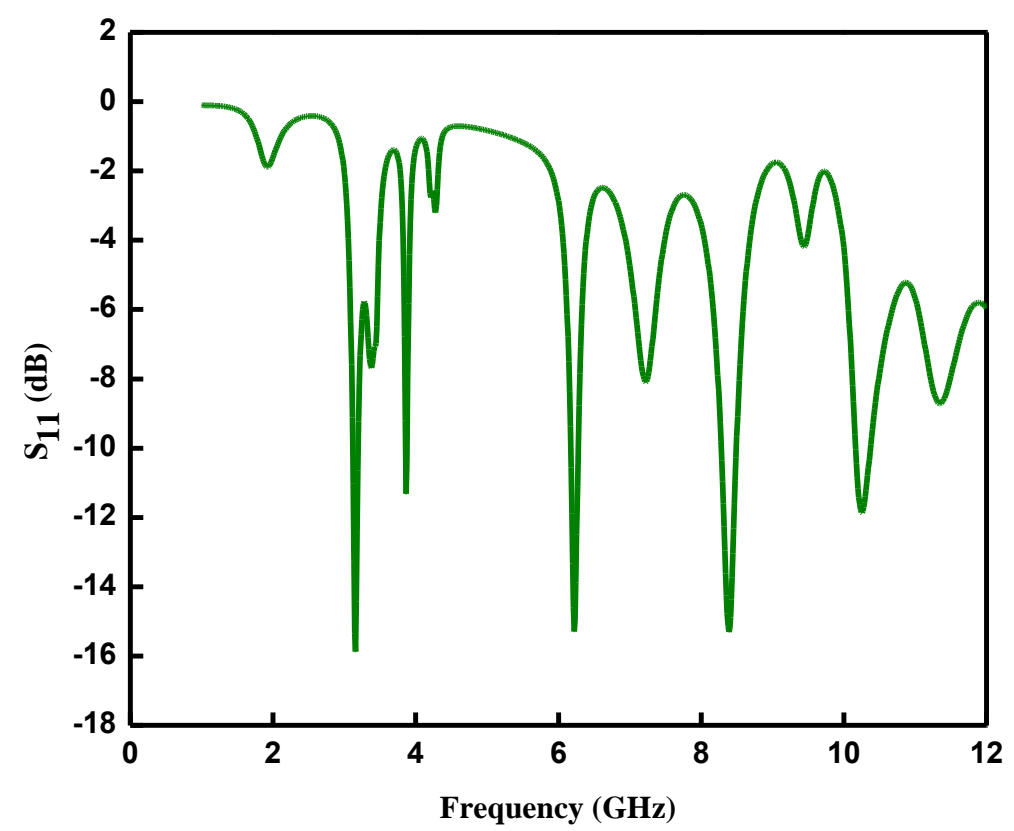

Figure 2. $S_{11}$ Parameter of the Proposed Antenna Geometry

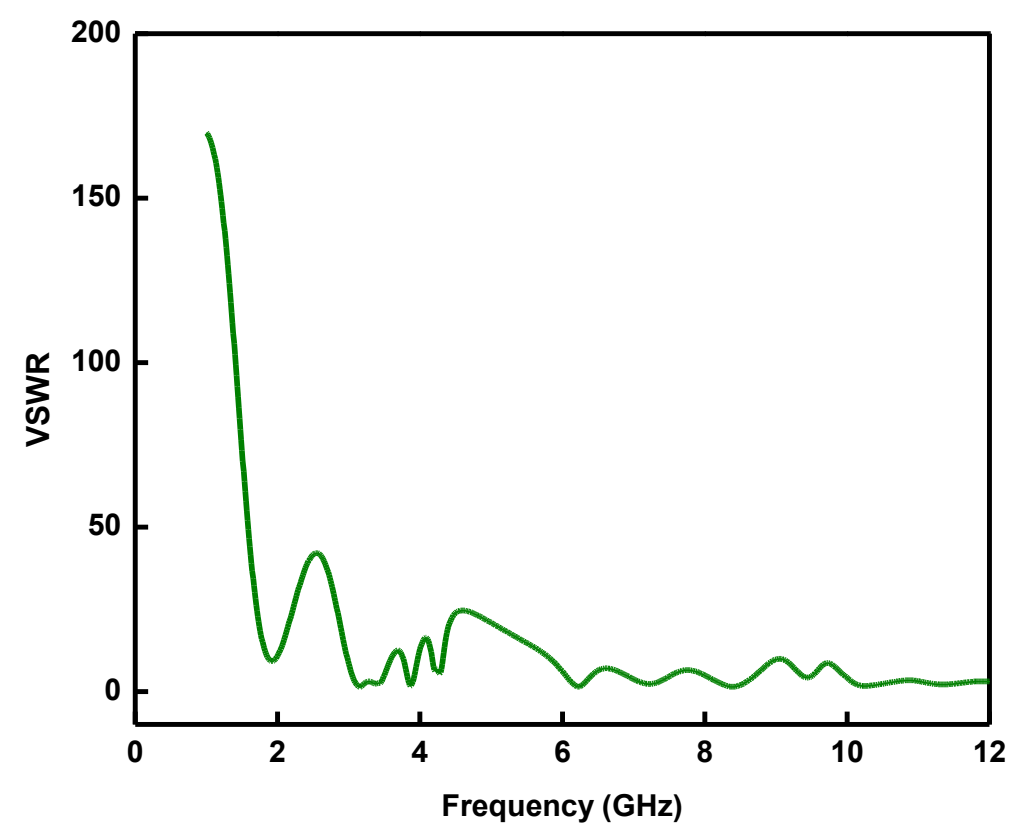

Figure 3. VSWR for the Proposed Antenna Geometry 
The Table 2 lists the frequency distributions, return loss, VSWR, and bandwidth covered by the simulated antenna geometry.

Table 2. Simulated Results of Designed Antenna Geometry

\begin{tabular}{|c|c|c|c|c|c|}
\hline \multicolumn{3}{|c|}{ Frequency } & $\begin{array}{c}\text { Return } \\
\text { loss/: } \mathbf{S}_{\mathbf{1}} \\
(\mathbf{d B})\end{array}$ & VSWR & $\begin{array}{c}\text { Bandwidth } \\
(\mathbf{M H z})\end{array}$ \\
\hline 3.122 & 3.155 & 3.188 & 15.867 & 1.383 & 66 \\
\hline 3.866 & 3.877 & 3.877 & 11.312 & 1.746 & 11 \\
\hline 6.177 & 6.222 & 6.266 & 15.288 & 1.415 & 89 \\
\hline 8.288 & 8.388 & 8.488 & 15.304 & 1.414 & 200 \\
\hline 10.166 & 10.255 & 10.366 & 11.856 & 1.685 & 200 \\
\hline
\end{tabular}

The Figure 4 (a), (b), and (c) shows radiating patch on front side, ground plane on back side, and base mounted SMA coaxial connector on FR4 substrate

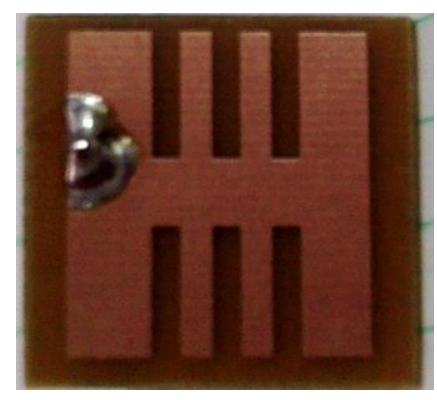

(a)

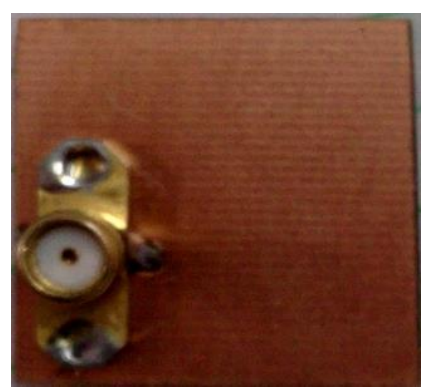

(b)

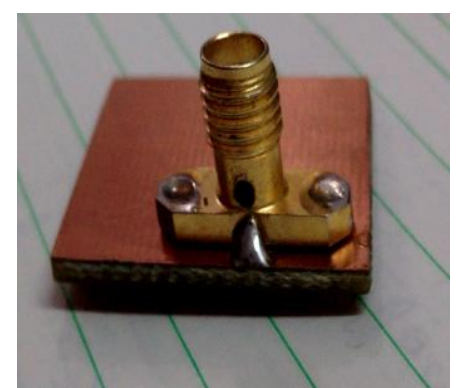

(c)

Figure 4. (a) Radiating Patch on Front Side, (b) Ground Plane on Back Side, and (c) Base Mounted SMA Coaxial Connector

The fabricated antenna was tested with VNA tool with frequency range from 1 to 12 GHz. The fabricated antenna successfully demonstrated five frequency bands including C-Band and X-Band. The Figure 5 shows return loss plots for fabricated antenna. 


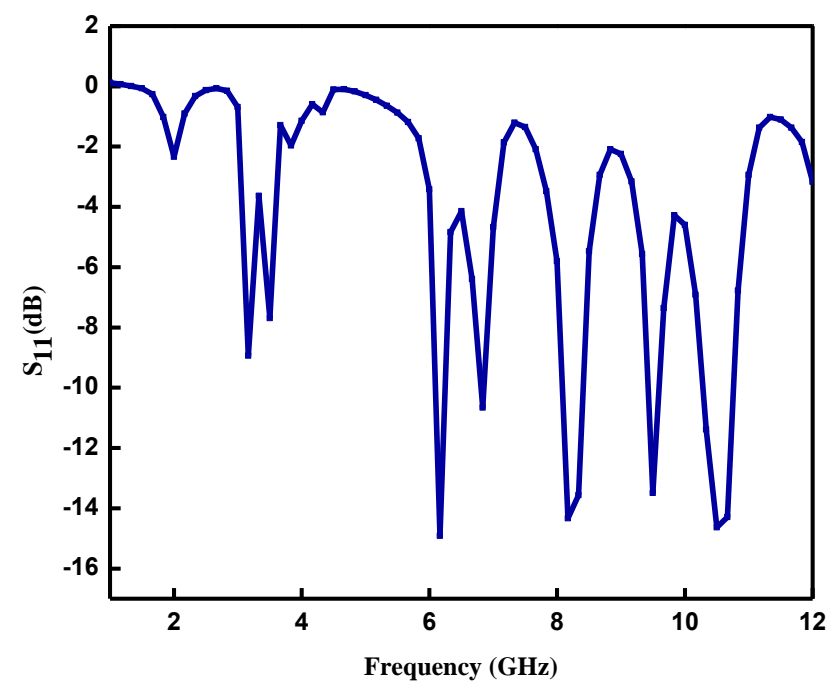

Figure 5. Return Loss of the Fabricated Antenna

The Figure 6 describes the VSWR plot for the fabricated antenna geometry.

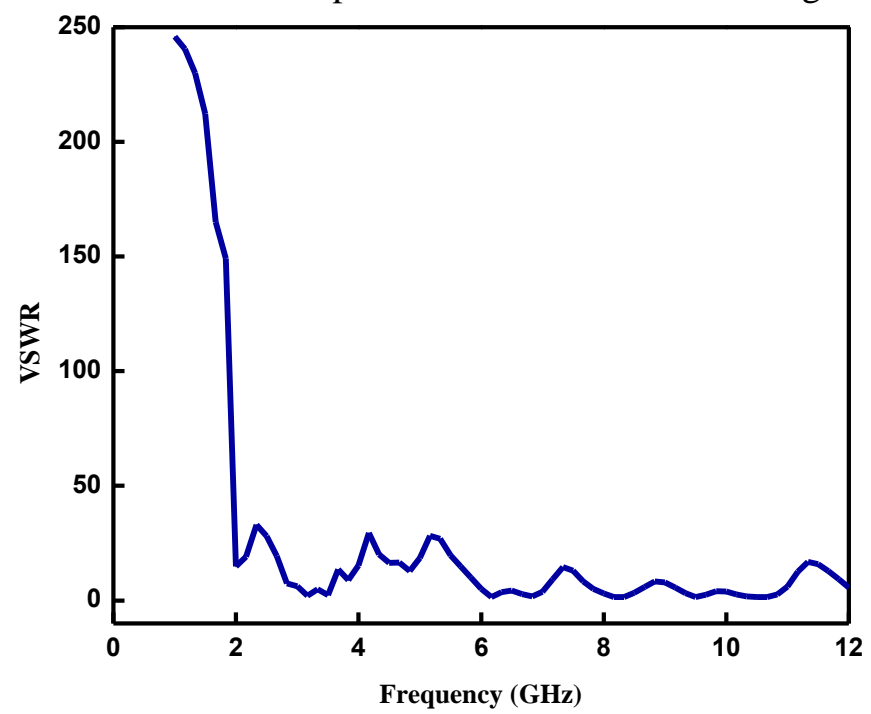

Figure 6. VSWR of the Fabricated Antenna

The Table 3 lists the frequency distributions, return loss, VSWR, and bandwidth covered by the fabricated antenna geometry.

Table 3. Measured Results of Fabricated Antenna Geometry

\begin{tabular}{|c|c|c|c|c|c|}
\hline \multicolumn{3}{|c|}{ Frequency } & $\mathbf{S}_{\mathbf{1 1}}$ & VSWR & $\begin{array}{c}\text { Bandwidth } \\
(\mathbf{M H z})\end{array}$ \\
\cline { 1 - 3 } $\mathbf{F}_{\mathbf{I}}$ & $\mathbf{F}_{\mathbf{c}}$ & $\mathbf{F}_{\mathbf{h}}$ & & & 100 \\
\hline 6.10 & 6.166 & 6.2 & 14.9 & 1.43 & - \\
\hline- & 6.833 & - & 10.7 & 1.82 & - \\
\hline 8.10 & 8.166 & 8.35 & 14.3 & 1.48 & 250 \\
\hline 9.48 & 9.500 & 9.52 & 13.5 & 1.54 & 40 \\
\hline 10.333 & 10.500 & 10.666 & 14.6 & 1.46 & 333.33 \\
\hline
\end{tabular}




\section{D and 3D Gain}

The frequencies covered falls in C-band and X-band. The 2D gain graphs for the optimized frequencies are shown in the Figure 7. The 3D gain plots are shown in Figure 8. It gives a total gain of $2.96 \mathrm{~dB}$ which is at a frequency of $10.33 \mathrm{GHz}$.

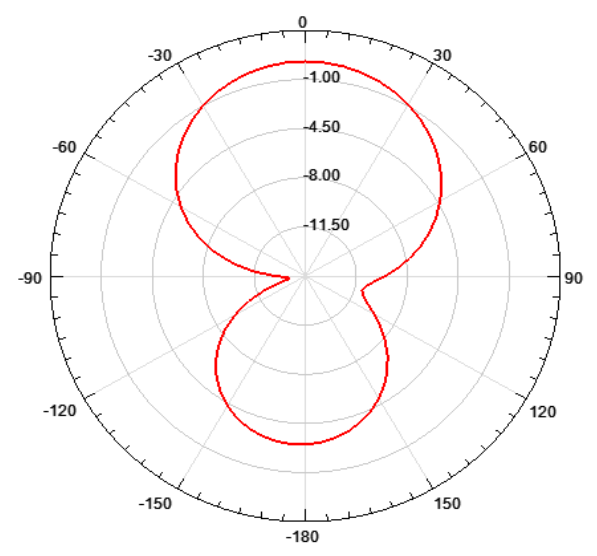

(a) $3.155 \mathrm{GHz}$

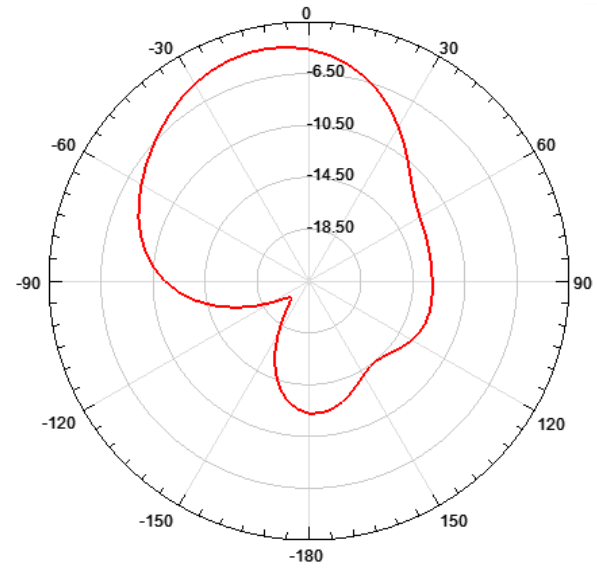

(c) $6.222 \mathrm{GHz}$

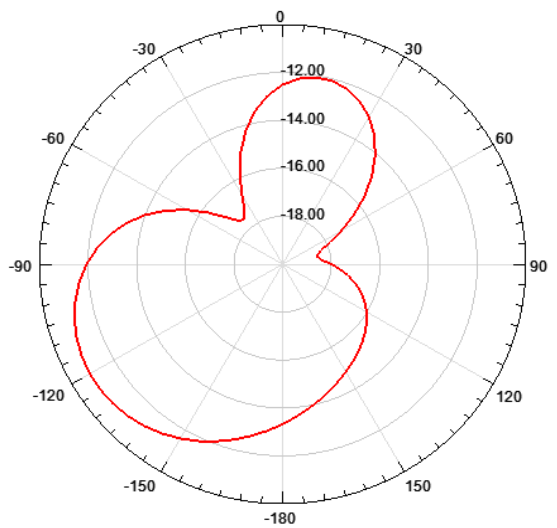

(b) $3.866 \mathrm{GHz}$

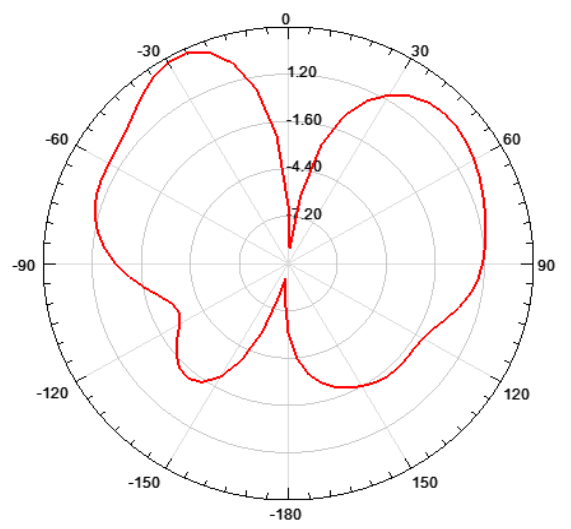

(d) $8.388 \mathrm{GHz}$

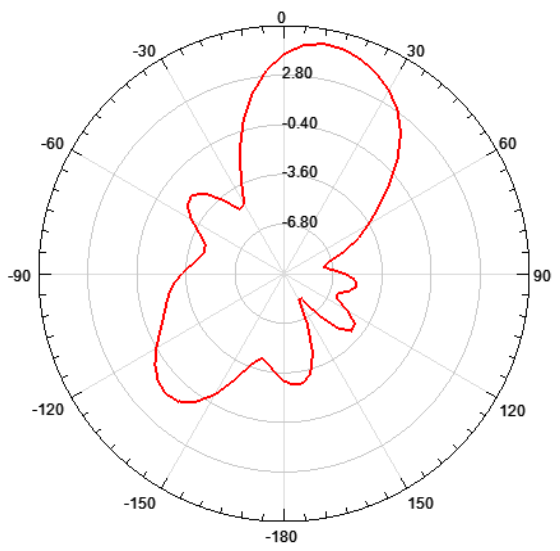

(e) $10.255 \mathrm{GHz}$

Figure 7. 2D Radiation Pattern of Designed Antenna at (a) $3.155 \mathrm{GHz}$, (b) 3.866 GHz, (c) $6.222 \mathrm{GHz}$, (d) $8.388 \mathrm{GHz}$, and (e) $10.255 \mathrm{GHz}$ Frequencies 

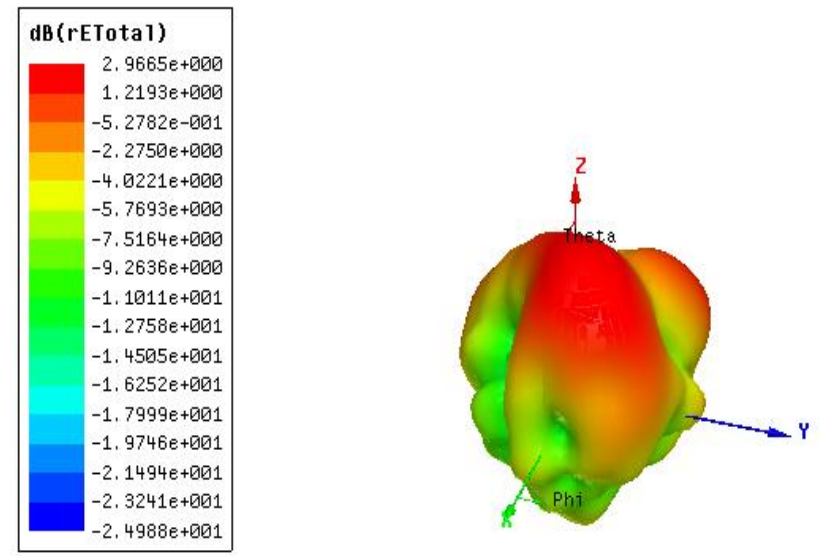

Figure 8. 3D Gain Plot of Designed Antenna Geometry

\section{Conclusion}

The fabricated Microstrip patch antenna successfully demonstrated five frequency bands from $6.1 \mathrm{GHz}$ to $10.6 \mathrm{GHz}$. The C-band covers $4-8 \mathrm{GHz}$ and X-band covers 8-12 GHz. C-band is employed in satellite communications and X-band is mostly used in military applications. So, it is observed that designed microstrip patch antenna structure is suitable for these applications. In case of X-band, the radio communication and radar applications are used. The fabricated E-shaped microstrip antenna characterizes five resonant frequency peaks at $6.166,6.833,8.166,9.500$ and $10.500 \mathrm{GHz}$ with return loss of $-14.9,-10.7,-14.3,-13.5$ and $-14.6 \mathrm{~dB}$ respectively. The values of VSWR exhibited at resonant frequency peaks are $1.43,1.82,1.48,1.54$ and 1.46 respectively. It is observed that the designed antenna exhibits multiband operation along with compactness in size. Therefore, this compact size antenna can be successfully employed for wireless applications and can be embedded easily in any portable device due to its small size.

\section{References}

[1] M. I. Nawaz, Z. Huiling, M. S. S. Nawaz, K. Zakim, S. Zakim and A. Khan, "A Review on Wideband Microstrip Patch Antenna Design Techniques", Proceedings of International Conference on Aerospace Science \& Engineering (ICASE) (IEEE), (2013), pp. 1-8.

[2] A. Kaushal and S. Tyagi, "Microstrip Patch Antenna its Types, Merits Demerits and its Applications", International Journal of Engineering Science and Research Technology (IJESRT), ISSN: 2277-9655, (2015) July, pp. 619-622.

[3] P. K. Deb, T. Moyra and P. Bhowmik, "Dual Band Multilayer E-Shape Microstrip Patch Antenna for CBand and X-Band", Proceedings of $2^{\text {nd }}$ International Conference on Signal Processing and Integrated Networks (SPIN) (IEEE), (2015), pp. 30-34.

[4] T. F. A. Nayna, A. K. M. Baki and F. Ahmed, "Comparative Study of Rectangular and Circular Microstrip Patch Antennas in X Band", Proceedings of International Conference on Electrical Engineering and Information \& Communication Technology (ICEEICT), (2014), pp. 1-5.

[5] N. Parmar, M. Saxena and K. Nayak, "Review of Microstrip Patch Antenna for WLAN and Wi-Max Application", International Journal of Engineering Research and Applications, vol. 4, no. 1, pp. 168171, (2014) January.

[6] W. Afzal, M. M. Ahmed and F. A. Mughal, "L-Shaped Multiband Microstrip Patch Antenna for DCS and WLAN Applications", Proceedings of $9^{\text {th }}$ International Conference on Emerging Technologies (ICET) (IEEE), (2013), pp. 1-5.

[7] M. T. Ali, N. Nordin, I. Pasya and M. N. M. Tan, "H-Shaped Microstrip Patch Antenna Using L-Probe Fed for Wideband Applications", In Proceedings of $6^{\text {th }}$ European Conference on Antenna and Propagation (EUCAP) (IEEE), (2012), pp. 2827-2831.

[8] “Cisco." http://www.cisco.com/c/en/us/support/docs/wireless-mobility/wireless-lan-wlan/82068-omnivs-direct.html, (2007) February.

[9] “Antenna Basics,” http://www.antenna-theory.com/m/basics/main.php, (2015) November 20. 
[10] A. Elrashidi, K. Elleithy and H. Bajwa, "Input Impedance, VSWR and Return Loss of a Conformal Microstrip Printed Antenna for TM 10 Mode Using Polymers as a Substrate Materials," American Journal of Plant Science(AJPS), (2013).

[11] H. K. Dubey and D. Arya, "Design and Simulation of Multiband Microstrip Patch Antenna Using Slot Technique for Wireless Communication”, International Journal of Engineering Research (IJOER), vol. 4, no. 1, pp. 47-49, (2016) January-February.

[12] A. Elrashidi, K. Elleithy and H. Bajwa, "Resonance Frequency, Gain, Efficiency and Quality Factor of a Microstrip Printed Antenna as a Function of Curvature for TM01 Mode Using Different Substrates", Journal on Wireless Communications and Networking (EURASIP), (2011) July.

[13] A. Singh and S. Singh, "A Trapezoidal Microstrip Patch Antenna on Photonic Crystal Substrate for High Speed Thz Applications", Photonic and Nanostructures-Fundamentals and Applications (ScienceDirect), vol. 14, (2015) January, pp. 52-62.

[14] S. A. H. Saghanezhad and Z. Atlasbaf, "Miniaturized Dual-Band CPW-Fed Antennas Loaded with UShaped Metamaterials", IEEE Antennas and Wireless Propagation Letters, vol. 14, (2015), pp. 658-661.

[15] A. Singh and S. Singh, "A Novel CPW-Fed Wideband Printed Monopole Antenna with DGS", AEUInternational Journal of Electronics and Communications (Science- Direct), vol. 69, no. 1, pp. 299-306, (2015) January.

[16] J. Abraham, A. John K K and T. Mathew, "Microstrip Antenna Based on Durer Pentagon Fractal Patch for Multiband Wireless Applications", In proceedings of International Conference on Information Communication and Embedded Systems (ICICES) (IEEE), (2014), pp. 1-5.

[17] A. Majumder, "Design of an H-Shaped Microstrip Patch Antenna for Bluetooth Applications", International Journal of Innovation and Applied Science (ISSR), vol. 3, no. 4, (2013) August, pp. 987994.

[18] Z. N. Chen Nazimuddin and X. Qing, "Slotted Microstrip Antennas for Circular Polarization with Compact Size", In proceedings of Antennas and Propagation Magazine (IEEE), vol. 55, no. 2, pp. 124137, (2013) April.

[19] R. V. Chaudhari and I. Parmar, "Review on Techniques for Microstrip Patch Antenna Gain \& Bandwidth Enhancement", International Journal of Engineering and Innovative Technology (IJEIT), vol. 2, no. 9, (2013) March, pp. 149-152.

[20] I. Singh, V. S. Tripathi and S. Tiwari, "Compact Circularly-Polarized Microstrip Patch Antenna on Reactive Impedance Substrates", In proceedings of $5^{\text {th }}$ International Conference on Computers and Devices for Communication (CODEC) (IEEE), (2012), pp. 1-4.

[21] H. Patel, S. K. Patel, J. Bhalani and Y. Kosta, "Design of Meandered H-Shaped Square Microstrip Patch Antenna", In proceedings of Nirma University International Conference on Engineering (NUiCONE), (2012), pp. 1-4.

[22] M. D. Sharma, A. Katariya and R. S. Meena, "E Shaped Patch Microstrip Antenna for WLAN Application Using Probe Feed And Aperture Feed", In proceedings of International Conference on Communication Systems and Network Technologies (CSNT) (IEEE), (2012), pp. 66-70.

[23] Y. Sung, "A Printed Wide-Slot Antenna With a Modified L-Shaped Microstrip Line for Wideband Applications", In IEEE Transactions on Antennas and Propagation, vol. 59, no. 10, (2011) October, pp. 3918-3922.

[24] Y. Kumar and S. Singh, "A Compact Multiband Hybrid Fractal Antenna for Multistandard Mobile Wireless Applications", Wireless Personal Communications (WPC), vol. 82, no. 2, (2015) April 28.

[25] Y. Kumar and S. Singh, "A Quad-Band Hybrid Fractal Antenna for Wireless Applications", in proceedings of IEEE International Advance Computing Conference (IACC), (2015), pp. 730-733.

[26] Y. Kumar and S. Singh, "Microstrip Fed Multiband Hybrid Fractal Antenna for Wireless Applications", Aces Journal, vol. 31, no. 3, (2016) March, pp. 327-332. 
International Journal of Signal Processing, Image Processing and Pattern Recognition Vol. 9, No. 10, (2016) 